\title{
Computational Analysis for Estimating Electricity Wastage in Buildings
}

\author{
P. A. Ozoh \\ Dept of ICT \\ Osun State University \\ Osogbo, Nigeria
}

\author{
A. A. Adigun \\ Dept of ICT \\ Osun State University \\ Osogbo, Nigeria
}

\author{
L. O. Omotosho \\ Dept of ICT \\ Osun State University \\ Osogbo, Nigeria
}

\begin{abstract}
Computational analysis is a collection of procedures that is used to process large amounts of data with a view of obtaining results based on processed data and as a result, getting their behavioral pattern. The main goal of this research is to determine the amount of electricity wastage and to study occupant's attitude towards energy conservation. In this research, computational techniques are applied to analysis of data collected collected from the Faculty of Computer Science and Information Technology (FCSIT) building, Universiti Malaysia Sarawak (UNIMAS), Malaysia which is considered as the case study. Data collection is carried out by questionnaire analysis of electricity consumers. The questionnaires consists of information on building occupants turning off lights in rooms with no presence, and occupants limiting electricity consumption in the building. This was achieved by administering questionnaires on the FCSIT staffs and students. The information collected provides real-time data on electricity consumption for the building over different periods of time. To effectively model electric wastage in the building, a simulation must be carried out to accurately model the actual amount of electricity consumed in the building and at what period of time. The simulation is based on the real system is built to estimate the amount of electricity wastage at the FCSIT building. Electricity consumption in the building is based on real electricity consumption using statistical analysis. A goodnesstests which consist of the Chi-Square $\left(\chi^{2}\right)$ goodness-test is computed to ensure that the resulting model is reliable and adequate.
\end{abstract}

\section{Keywords}

Computational analysis, behavioral pattern, simulation, energy savings, goodness-tests.

\section{INTRODUCTION}

Electricity consumption for Universiti Malaysia Sarawak (UNIMAS) air-conditioning, light and others are centrally controlled using a Building Automation System (BAS), where the timers for air-conditioning and lights are set through a central computer. For example; all air-conditioners on campus are set from 7.30a.m. to 5.00 p.m. everyday except for weekends. Yet, not all of the teaching facilities are being utilized all the time. Besides, the current system prevents the manual switching off of air-conditioning at some places such as lecture hall, individual lecturer rooms, etc. Therefore, it may lead to electricity wastage as it may not be utilized during nonlecture periods. In other cases where lectures are canceled or changed to another time, the air-conditioning and lights in lecture halls might be left on if the division staffs are not informed of the change in time. According to UNIMAS Asset Division about $70 \%$ of UNIMAS electricity bill is due to airconditioning usage. In addition, computers in computer laboratories are not even switched off after use. Lights, airconditioning and LCD projectors at the tutorial room or teaching hall are usually left on after lectures. Similarly, toilet lights also are not been switched off after being used. They are even left on overnight or over the weekends. According to SESCO (Sarawak Electricity Supply Corporation), UNIMAS electricity rate is categorized as commercial and it is estimated that UNIMAS paid about RM 1.3 million (About US\$ 200,000) per month for electricity bills.

The specific aims of this study are as follows:

(i) To study electricity wastage.

(ii) To study the user attitude towards energy conservation.

(iii) To give recommendations on an effective solution in reducing the cost of electricity wastage.

The present work will study electricity wastage and propose the appropriate solution that will help to reduce the value of UNIMAS electricity bills. In addition it will also simulate the usage trend in order to get more accurate results. As a result, the contributions to research of this paper are as follows:

1) To reduce electricity wastage.

2) To encourage energy conservation in buildings, and as a result

3) To reduce the cost of electricity bills.

\section{LITERATURE REVIEW}

Developments in the field of computational analysis is often parallel or follow advancement in those fields whereby statistical computing is applied. It is because computational analysis often address particular applied decision problems, methods developments is consequently motivated by the search to better decision making under uncertainties. "World Energy Outlook (2019) in its presentation identified applying computational analysis techniques for planning and management in the energy market as a means of improving efficient electricity consumption in electrical appliance use. The study indicated that the introduction of new techniques in analyzing energy models would "minimize economic losses, since this has become a tool for optimizing energy resources and accurately allocating energy resources, thus improving efficiency in electric appliance use.

"Due to the importance of having an efficient electricity consumption system, various studies have addressed the issue of finding a solution to this problem. This varies from the use of sensors, which regulates and control electric usage, to the efficient allocation and scheduling of electric power supply" (Aswani et al., 2012). Zamri et al. (2011) examines the possibility of saving energy in selected buildings. The research paper aims at reducing electrical energy consumption. The 
process includes selecting appropriate building, energy usage pattern, user attitude toward energy conservation, technical measures and economic analysis. The research paper investigates electricity consumption for the subject area and involved all electrical components such as lighting, air conditioning.etc. The study was carried out with the help of a survey by distributing questionnaires and conducting interviews to study users' behavioral pattern. Results from the study indicate that electricity consumption for the selected building varies according to time (e.g. semester break, holidays, convocation etc.). As discussed by Oldewurtela et al., 2012, "Electricity enables the use of daily appliances (such as computers, medical devices, and telecommunication appliances) that increase people's quality of life. Most appliances used in daily life are powered by energy and it is generally regarded to be almost impossible to live without them. As a result, energy is seen as a necessity for social and economic welfare; it is essential to maintain economic activity in modern industrialized nations and social development". This call for proper resource allocation and supply from the electricity network in order to reduce energy consumption through the application of control techniques.

In order to perform reliable decision making, it is expedient to accurately model real life problems in diverse applications in order to accurately estimate electricity consumption and wastage in buildings, otherwise inappropriate models and poor estimates may occur. (Ozoh et al., 2018). The paper indicates that electricity consumption demonstrates a regular behaviour over a period of time. The ability to model and perform decision modeling and analysis is an essential feature of many real-world applications ranging from emergency medical treatment in intensive care units to military command and control systems (Ozoh et al., 2018). The paper presented that models are essential in providing support for businesses processes, systems and dealing with complex problems. The development of appropriate models for planning and management is a tool for improving efficiency in real world problems. Farhanieh and Sattari (2006) studied the effects of insulation on energy savings in buildings. For this purpose, an integrative modelling is used for simulating the energy consumption in buildings. Lei and Ning (2009) discussed the development of algorithms for the minimization of electric production costs of power by combining genetic algorithms and Newton's method. The algorithm is effective in providing power system dispatchers with accurate estimates, resulting in improved efficiency in appliance usage.

A study to examine the impact of alternative energy saving measures on energy requirements in office buildings in hothumid climates was conducted by (Iqbal \& Al-Homoud, 2007). In the research carried out, different types of Heating, Ventilation, and Air-Conditioning (HVAC) systems were chosen and different feasible and practical operational energy saving measures (ESM) were evaluated using the energy simulation software Visual DOE 4.0. Data was collected through a review of design drawings, building audit and the analysis of 4 years electricity utility bills. All the collected data were analyzed and the utility bills data was used to standardize the base case of the existing building using Visual DOE energy simulation software. ("Office of Energy Efficiency", 2010) investigates how facility managers in schools calculate their energy performance, comparing it with benchmarks in the same region and across Canada. Firstly, they determined the main areas that can be improved upon and locate where the energy is being used. In this case, about 15000 schools in Canada are being administrated by about 495 school boards. Data for energy consumption for these schools was collected and analyzed in order to prepare bench marking guides. Data collected varies according to some manipulative factors such as location, climate, occupancy, building age and also the level within the sector that include school boards, individual schools and similar schools. The research paper represents data graphically using trend lines, which was analyzed using statistical techniques in the form of regression analysis. From results obtained from the study, benchmark data can be used by schools to determine the state of their energy performance and then by using trend lines, schools can calculate average performance for their site or student numbers and then make comparison with their current energy use.

(Hartungi \& Jiang, 2011) discusses obtaining information about the cooling systems and plug loads, conducting a walk-through energy audit in buildings and finding out low costs processes that could be implemented to reduce energy. The study involves selecting a building as a subject material and carrying out a detailed energy audit with the permission from the building management. Data was simulated with the aid of the Energy-10 software. As a result, a few energy saving measures were recommended for this particular building and the energy consumption was found decreased after those measure was implemented. Energy analysts need the guidelines for choosing the most appropriate computational technique to provide accurate estimates for electricity consumption in buildings. Social, economic, weather and environmental factors are found to affect electricity consumption. This results in monthly, daily and hourly variations in electricity consumption pattern. This makes it necessary for decision making to be inferred from modelling electricity consumption in order to allocate energy resources in an efficient manner (Yao el al., 2000).

\section{METHODOLOGY}

This section discusses data collection methods, findings from occupants' attitudes towards energy conservation which was conducted by distributing questionnaires to faculty of computer science and information technology (FCSIT) staffs and students. This section also discusses the simulation used in this study which involves analyzing the data collected using Chi-Square $\left(\chi^{2}\right)$ data analysis goodness-test procedure.

\subsection{Data Collection}

For data collection, population and sample must be clearly identified for which inference would be made where all requirements of sampling and experimental design must be satisfied. The research samples are given as follows:

\section{Population:}

$>$ All toilets, tutorial room and lecture hall at FCSIT Sample:

$>$ FCSIT :

○ Toilets at ground level

○ Lecture room 6

The research sample is given in Figure 1. 


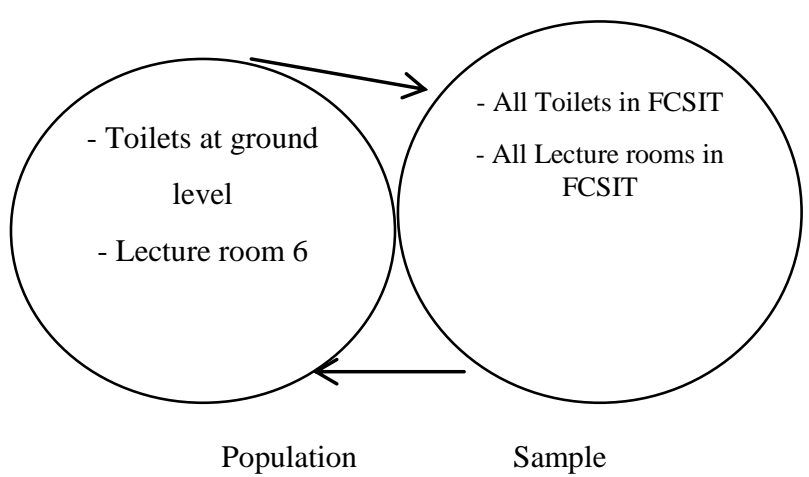

Figure 1. Research sample for data collection

The samples are picked using random sampling method where all subjects that is in the population have equal chances of been chosen. For this research, each toilet and tutorial room in the faculty of computer science and information technology (FCSIT) building is given a number. Then Excel was used to generate random numbers to create a group of sample. Data collection was carried out for 21 days, randomly, between 20 Feb 2015 - 22 Jun 2015 on weekdays except during semester breaks and public holidays.

Observation technique was used to calculate the duration of time electricity is unnecessarily used. For example, in toilet on the ground floor, Student A enters the toilet for about 5 minutes. Electricity is not switched off after he leaves the toilet. After 5 minutes, student $\mathrm{B}$ walks in. Duration for the electricity consumed is calculated from the time Student A leaves the toilet and the time Student B enters. The design for data collection and electricity wastage is shown in Table 1 .

Table 1. Observation data for Toilet in ground level

\begin{tabular}{|c|c|c|c|c|c|c|}
\hline & Arrive & $\begin{array}{c}\text { Depar } \\
\mathrm{t}\end{array}$ & $\begin{array}{c}\text { Stay } \\
\mathrm{m} \\
\mathrm{m}: \mathrm{s} \\
\mathrm{s})\end{array}$ & $\begin{array}{c}\text { Switc } \\
\mathrm{h} \\
\text { on/off }\end{array}$ & $\begin{array}{c}\text { Roo } \\
\mathrm{m} \\
\mathrm{empt} \\
\mathrm{y} \\
(\mathrm{Y} / \mathrm{N} \\
)\end{array}$ & $\begin{array}{c}\text { Wastage } \\
\text { (hh:mm:ss } \\
\text { ) }\end{array}$ \\
\hline A & $\begin{array}{c}8: 35: 0 \\
1 \mathrm{AM}\end{array}$ & $\begin{array}{c}8: 38: \\
56\end{array}$ & $\begin{array}{c}\text { AM } \\
: 55\end{array}$ & On & $\mathrm{N}$ & $00: 04: 27$ \\
\hline B & $\begin{array}{c}8: 43: 2 \\
9 \mathrm{AM}\end{array}$ & $\begin{array}{c}8: 48: \\
00 \\
\mathrm{AM}\end{array}$ & $\begin{array}{c}5 \\
: 29\end{array}$ & On & $\mathrm{Y}$ & \\
\hline
\end{tabular}

In lecture room 6, a lecturer is having a class from 9a.m to 11 p.m. Later, after classes, the projector, lights are not switched off, also the PC is not changed to sleep mode. The next class that will be held at lecture room 6 is at 2p.m. The duration for the room is vacant will be taken into account. The room is checked every 2 hours to see whether the equipment is still on the same condition as it left. Table 2 shows the design of the data collection for observation data:
Table 2. Observation data for lecture room

\begin{tabular}{|c|c|}
\hline Time & Monday \\
\hline $8-9$ & \\
\hline $9-10$ & \\
\hline $10-11$ & \\
\hline $11-12$ & On \\
\hline $12-1$ & On \\
\hline $1-2$ & On \\
\hline $2-3$ & On \\
\hline $3-4$ & On \\
\hline $4-5$ & On \\
\hline
\end{tabular}

A survey is conducted by distributing respondents' attitudes towards energy conservation (ATEC) questionnaires to study occupants' behavior. The occupants'attitude towards energy conservation used in this study contains 15 questions with multiple choices and in likert scale format. Likert scale is anchored at both ends ( $1=$ Strongly Disagree and 5= Strongly Agree). ATEC is composed of two parts; (i) 7 questions on top was to measure the respondent behavior pattern of the energy usage, and (ii) 8 questions with likert scale to measure the respondent awareness of the energy conservation. The questionnaires were distributed to two selected samples which are FCSIT staffs and students. The selected samples consisted of 40 staffs and 60 students. They were selected randomly based on their availability.

\subsubsection{Findings from occupants' attitude towards energy conservation}

The occupants' attitudes towards energy conservation questionnaires were analyzed separately between staffs (40 questionnaires) and students (60 questionnaires). The findings reflect FCSIT staffs and students behavior pattern towards energy conservation. Excel spreadsheet was used to plot the graphs. The results obtained from analyzing then questionnaires are given as follows:

Figure 2 shows how staff and students leave their personal computer (PC) or laptop when not in used. Most of the staff shut their PC or laptop when they are not using it about 21 people or $52.5 \%$ of them. 14 people or $35 \%$ of them put the PC or laptop in standby mode and only 5 people or $12.5 \%$ left the PC or laptop on even when unused. There are 25 people or $41.7 \%$ of the students who put their PC or laptop in standby mode when they not using it. Meanwhile, there are 23 people or $38.3 \%$ of them who shut down their PC or laptop and there only 12 person or $20 \%$ of them who left their PC or laptop on. 


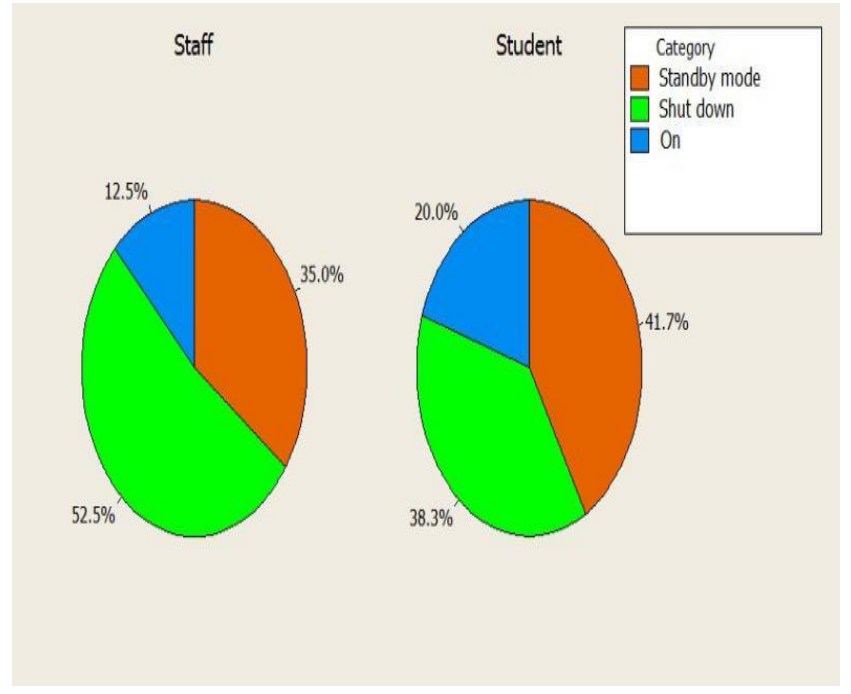

Figure 2. Personal Computer (PC) or laptop mode when not in use

Figure 3 shows the percentage on the average frequency of personal computer or laptop left on when FCSIT staffs and students leaving their room. The most frequent of average time that FCSIT staffs left their PC or laptop on is more than an hour which is 14 people or $35 \%$ of them. Then there are $15 \%$ of FCSIT staffs or 6 people chose 10 to 15 minutes and 5 to 10 minutes. Lastly, only $10 \%$ of FCSIT staffs or 4 people stated they never left their PC or laptop on. 41.7\% of FCSIT students or 25 people stated the average frequency they left their PC or laptop on while leaving the room is more than an hour. $28.3 \%$ of FCSIT students or about 17 people chose 15 to 30 minutes.10\% of the FCSIT students or 6 people chose 10 to 15 minutes and 5 to 10 minutes as their average time they left their PC or laptop on. 6 persons or $10 \%$ of the students stated they never left their $\mathrm{PC}$ or laptop on while leaving the room.

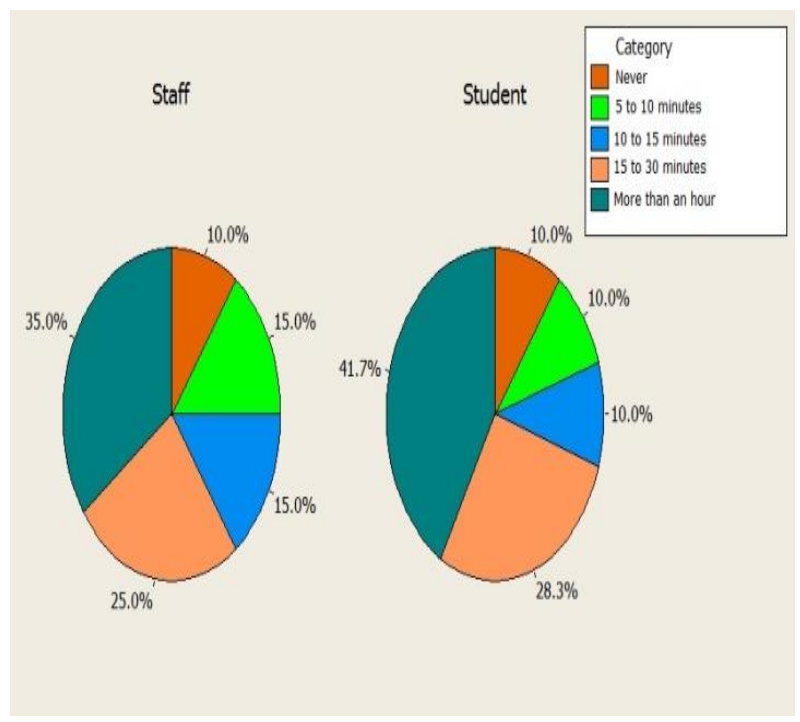

Figure 3. The average frequency of personal computer or laptop left on when leaving room

Figure 4 shows the frequency lights are switched off when the last person leaves the room. For the FCSIT staffs, there are $62.5 \%$ of them or 25 people that switch off the lights when they are the last person to leave the room. There are $7.5 \%$ or 3 people that rarely switch off the lights when they are the last person to leave the room. 1 person or $2.5 \%$ never switch off the lights. The frequency for FCSIT students for every time is $36.7 \%$ or 22 people. The frequency for rarely switch off lights is $7.5 \%$ or 3 people, while 1 person or $2.5 \%$ never switches off lights.

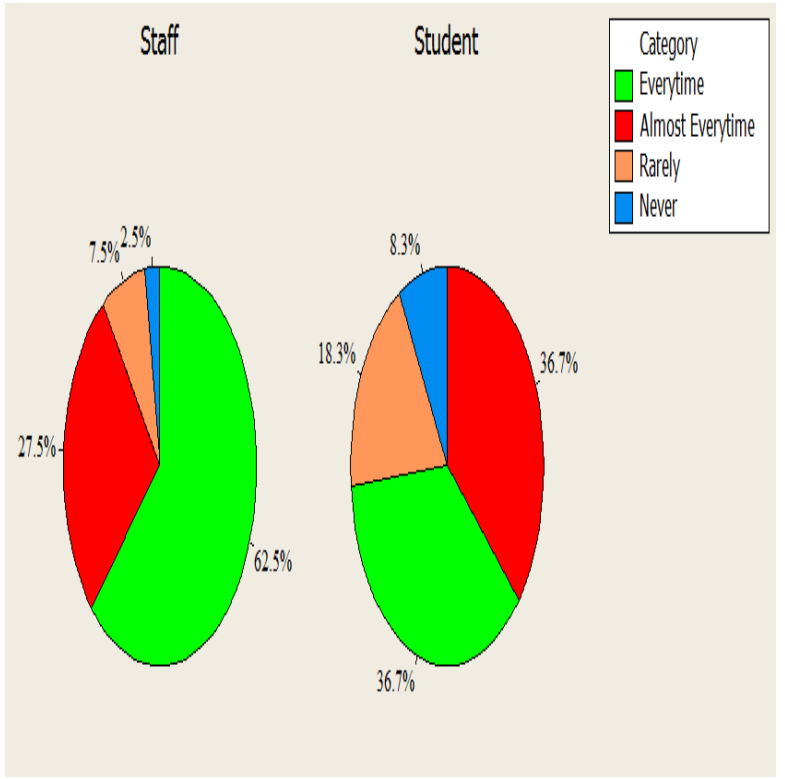

Figure 4. Frequency of switching off lights when the last person leaves room

\subsubsection{Simulation results}

The Chi-Square $\chi 2$ data analysis goodness-test procedure ${ }_{i} \mathrm{~s}$ applied in this study and is given in Table 3 .

Chi-Square $\chi 2$ is given as:

$\chi^{2}=\frac{\left(o_{i}-n p_{i}\right)^{2}}{n p_{i}}$

Where,

$O_{i}=$ observed values, $n=$ sample size, $k$ is the number of class intervals, and

$p_{i}=\frac{1}{k}$

Table 3. Chi-Square $\chi 2$ data analysis procedure

\begin{tabular}{|c|c|}
\hline Research Hypothesis & Data Source \\
\hline $\begin{array}{c}\text { Ho: the random variable is } \\
\text { exponentially distributed } \\
H_{l}: \text { the random variable is } \\
\text { not exponentially } \\
\text { distributed }\end{array}$ & $\begin{array}{c}\text { Observation data for toilet at } \\
\text { ground floor Monday- Friday (8 } \\
\text { AM - 1PM) }\end{array}$ \\
\hline
\end{tabular}

The computed results of the Chi-Square $\chi^{2}$ test for Monday, Tuesday, Wednesday, Thursday and Friday for toilet at ground floor level together with their respective table $\chi_{0.01}^{2}$ at $\alpha=0.01$ are given in Table 4. 
Table 4. Chi-Square Goodness-of-Fit Test for inter-arrival time for toilet at ground floor on Monday to Friday, February 25, 2015 (in minutes)

\begin{tabular}{|c|c|c|}
\hline Days & Computed Chi-Square $\left(\chi^{\mathbf{2}}\right)$ & $\chi_{0.01}^{2}$ \\
\hline Monday & 1.238 & 15.5 \\
\hline Tuesday & 13.024 & 15.5 \\
\hline Wednesday & 6.217 & 15.5 \\
\hline Thursday & 14.558 & 15.5 \\
\hline Friday & 14.229 & 17.5 \\
\hline
\end{tabular}

On Monday, the degrees of freedom is given by k-s-1 $=10-1-1$ $=8$. At $\alpha=0.05$, the table value of $\chi_{0.05,8}^{2}$ is 15.5 . Since $\chi_{o}^{2}<$ $\chi_{0.05,8}^{2}$

$\chi_{0.05,8}^{2}$, thus the null hypothesis is not rejected. Note that the

value of $\chi_{0.01,8}^{2}$ is 20.1 , so the null hypothesis would also not be rejected at level of significance $\alpha=0.01$. Thus, this test gives no reason that the data are poorly fitted by the exponential distribution.

For Tuesday, the degrees of freedom is given by k-s-1 = 10-1-1 $=8$. At $\alpha=0.05$, the table value of $\chi_{0.05,8}^{2}$ is 15.5. Since $\chi_{0}^{2}<$ $\chi_{0.05,8}^{2}$

$\chi_{0.05,8}^{2}$, thus the null hypothesis is not rejected. Note that the

value of $\chi_{0.01,8}^{2}$ is 20.1, so the null hypothesis would also not be rejected at level of significance $\alpha=0.01$. Thus, this test gives no reason that the data are poorly fitted by the exponential distribution.

For Wednesday, the degrees of freedom is given by k-s-1 $=10$ $1-1=8$. At $\alpha=0.05$, the table value of $\chi_{0.05,8}^{2}$ is 15.5 . Since $\chi_{0}^{2}<\chi_{0.05,8}^{2}$ thus the null hypothesis is not rejected. Note that

the value of $\chi_{0.01,8}^{2}$ is 20.1, so the null hypothesis would also not be rejected at level of significance $\alpha=0.01$. Thus, this test gives no reason that the data are poorly fitted by the exponential distribution.

On Thursday, the degrees of freedom is given by k-s-1 = 10-1-1 $=8$. At $\alpha=0.05$, the table value of $\chi_{0.05,8}^{2}$ is 15.5 . Since $\chi_{0}^{2}<$ $\chi_{0.05,8}^{2}$, thus the null hypothesis is not rejected. Note that the value of $\chi_{0.01,8}^{2}$ is 20.1 , so the null hypothesis would also not be rejected at level of significance $\alpha=0.01$. Thus, this test gives no reason that the data are poorly fitted by the exponential distribution.

For Friday, the degrees of freedom is given by k-s-1 = 10-1-1 = 8. At $\alpha=0.025$, the table value of $\chi_{0.025,8}^{2}$ is 17.5 . Since $\chi_{0}^{2}<$ $\chi_{0.0258}^{2}$

$\chi_{0.025,8}$, thus the null hypothesis is not rejected. Note that the

value of $\chi_{0.01,8}^{2}$ is 20.1, so the null hypothesis would also not be rejected at level of significance $\alpha=0.01$. Thus, this test gives no reason that the data are poorly fitted by the exponential distribution.

\subsubsection{Model building}

A few assumptions are applied which are as follows:

(i) Only one person enters the toilet at any one time.

(ii) The distribution of arrivals and duration times is the same for every week.

(iii) It is also assumed that there is no wastage after Saturday $8 \mathrm{AM}$ as the sample size for the data is small.

For the simulation of the toilet on the ground floor, heuristic model is presented and evaluated that effectively satisfies the problem. Heuristic model is a situation in which all relevant alternatives, their consequences, and probabilities are known, and where the future is certain, so that the optimal solution to a problem can be determined (Gaissmaier, 2011). Thus, the following variables are investigated:

$\lambda=$ the mean of user arrival rate

$\mu=$ duration rate

The arrival rate $(\lambda)$ and the duration rate $(\mu)$ are used in the simulation to generate the sequence of the arrival times. The results are given in Table 5 .

Table 5. The summary of arrival rate and duration rate for toilet in ground floor

\begin{tabular}{|c|c|c|c|}
\hline & Time interval & $\boldsymbol{\lambda}$ & $\boldsymbol{\mu}$ \\
\hline Monday & $8 \mathrm{AM}-1 \mathrm{PM}$ & 0.097 & 3.282 \\
\hline Tuesday & $8 \mathrm{AM}-1 \mathrm{PM}$ & 0.096 & 3.908 \\
\hline Wednesday & $8 \mathrm{AM}-1 \mathrm{PM}$ & 0.08 & 3.526 \\
\hline Thursday & $8 \mathrm{AM}-1 \mathrm{PM}$ & 0.089 & 3.910 \\
\hline Friday & $8 \mathrm{AM}-1 \mathrm{PM}$ & 0.096 & 3.682 \\
\hline
\end{tabular}

\subsubsection{Verification and validation of simulation} models

The validation test is conducted using historical input data to ensure that model will duplicate closely as possible the important events that occurred in the real system (Banks et al., 2000).The data that will be used is the duration of the real data (Monday 8AM-11AM) and the model output given in Table 6.

A paired-test was conducted to test $H_{0}=\mu_{d}=0$, or equivalently, $H_{0}: E\left(Z_{1}\right)=E\left(W_{1}\right)$, where $Z_{1}$ is the duration from the real system and $W_{1}$ is the duration predicted by the simulated model. Let the level of significance be $\alpha=0.05$. Using the results in Table 6 , the test statistic is

$$
t_{0}=\frac{\bar{d}}{\frac{s_{d}}{\sqrt{k}}}=\frac{0.723}{\frac{10.423}{\sqrt{87}}}=0.647
$$

The critical value is $\mathrm{t} \alpha / 2, \mathrm{~K}-1=\mathrm{t} 0.025,86=2.00$. Since $|\mathrm{t} 0|=$ $0.0647<\mathrm{t} 0.025,67$, the null hypotheses cannot be rejected on the basis of this test; that there is no inconsistency is detected between system output and model prediction. As a result, the 
simulated model is proven to be valid and it is assumed that the model is adequate to simulate the real world situation.

Table 6. Validation of the simulation

\begin{tabular}{|c|c|c|c|c|}
\hline $\begin{array}{c}\text { Input } \\
\text { Data } \\
\text { Set } \\
j\end{array}$ & $\begin{array}{c}\begin{array}{c}\text { Real- } \\
\text { System } \\
\text { output }\end{array} \\
z_{i j}\end{array}$ & $\begin{array}{c}\text { Model } \\
\text { Output } \\
w_{i j}\end{array}$ & $\begin{array}{c}\begin{array}{c}\text { Observed } \\
\text { Difference }\end{array} \\
d_{j}\end{array}$ & $\begin{array}{c}\begin{array}{c}\text { Squared } \\
\text { Deviation } \\
\text { from Mean }\end{array} \\
\left(d_{j}-\bar{d}\right)^{2}\end{array}$ \\
\hline 1 & 2.383 & 0.813 & 1.57 & 0.717 \\
\hline 2 & 0.967 & 5.565 & -4.598 & 28.318 \\
\hline 3 & 1.9 & 1.057 & 0.843 & 0.014 \\
\hline 4 & 1.833 & 1.753 & 0.08 & 0.414 \\
\hline 5 & 2.333 & 0.621 & 1.712 & 0.977 \\
\hline 6 & 0.65 & 0.834 & -0.184 & 0.824 \\
\hline 7 & 5.85 & 0.252 & 5.598 & 23.761 \\
\hline 8 & 2.8 & 0.287 & 2.513 & 3.202 \\
\hline 9 & 2.617 & 2.727 & -0.11 & 0.695 \\
\hline 10 & 3.117 & 0.892 & 2.225 & 2.255 \\
\hline 11 & 2.4 & 4.031 & -1.631 & 5.544 \\
\hline 12 & 5.817 & 8.678 & -2.861 & 12.848 \\
\hline 13 & 5.5 & 0.735 & 4.765 & 16.334 \\
\hline 14 & 3.05 & 1.724 & 1.326 & 0.363 \\
\hline 15 & 1.467 & 1.826 & -0.359 & 1.172 \\
\hline 16 & 1.217 & 0.249 & 0.968 & 0.06 \\
\hline 17 & 2.333 & 1.23 & 1.103 & 0.144 \\
\hline 18 & 2.65 & 1.199 & 1.451 & 0.529 \\
\hline 19 & 6.1 & 0.377 & 5.723 & 24.995 \\
\hline 20 & 1.633 & 0.538 & 1.095 & 0.138 \\
\hline 21 & 3.533 & 1.369 & 2.164 & 2.075 \\
\hline 22 & 6.7 & 4.226 & 2.474 & 3.064 \\
\hline 23 & 2.117 & 3.551 & -1.434 & 4.655 \\
\hline 24 & 1.117 & 0.3 & 0.817 & 0.009 \\
\hline 25 & 4.45 & 8.835 & -4.385 & 26.096 \\
\hline 26 & 6.5 & 1.775 & 4.725 & 16.012 \\
\hline 27 & 0.75 & 4.438 & -3.688 & 19.461 \\
\hline 28 & 4.417 & 0.054 & 4.363 & 13.246 \\
\hline 29 & 2.15 & 0.843 & 1.307 & 0.341 \\
\hline 30 & 4.433 & 4.292 & 0.141 & 0.339 \\
\hline . & • & . & . & . \\
\hline - & . & $\cdot$ & . & . \\
\hline$\cdot$ & $\cdot$ & • & $\cdot$ & $\cdot$ \\
\hline 87 & 1.2 & 0.665 & 0.535 & 0.036 \\
\hline & & & $\bar{d}=0.723$ & $S_{d}^{2}=10.428$ \\
\hline
\end{tabular}

\subsubsection{Analysis of electricity wastage}

Based on collected data, further analysis is needed for the calculation of estimating the cost of energy wasted in the FCSIT building and is given as follows:

(i) Total amount of hours spent on each electricity appliances that ranged in electricity wastage has been total up and obtain its average on each day.

(ii) The electricity appliance for the sample area is identified. Then, the electricity consumption for the electricity appliances mentioned has been searched online, and used to calculate the electricity wastage. In average, electricity consumption of the electricity appliances on wastage per day is calculated. The electric wastage is calculated using Table 1 .

(iii) Then, the cost of energy wasted is calculated using the tariff from Sarawak Energy which also known as SESCO. Universiti Malaysua Sarawak (UNIMAS) electricity bill is calculated using commercial pricing and electric tariff (C1).

From the simulation process given in Table 1, the estimate of electricity wastage for the toilet in ground level of FCSIT building for a semester is obtained and is displayed in Table 7 .

Table 7. Summary of estimated electricity wastage based on simulation

\begin{tabular}{|c|c|c|c|}
\hline Day & $\begin{array}{c}\text { Total } \\
\text { wastage hour }\end{array}$ & $\begin{array}{c}\text { Total } \\
\text { watt/hour }\end{array}$ & $\begin{array}{c}\text { Total } \\
\mathrm{kW} / \mathrm{hour}\end{array}$ \\
\hline Monday & 304.663 & 76775.076 & 76.775 \\
\hline Tuesday & 334.450 & 84281.400 & 84.281 \\
\hline Wednesday & 383.306 & 96593.112 & 96.593 \\
\hline Thursday & 339.707 & 85606.164 & 85.606 \\
\hline Friday & 301.375 & 75946.500 & 75.947 \\
\hline \multicolumn{2}{|l|}{} & $\sum$ & 419.202 \\
\cline { 3 - 4 } & & &
\end{tabular}

From Table 7, the cost of electricity wastage for toilet in ground floor is RM 148.55 (About US\$22).

\section{CONCLUSION AND FUTURE WORK}

In summary, the objectives of this research are achieved. The first objective of this research is to investigate the occurrence of electrical wastage in the FCSIT building. This was achieved by collecting data in the building. In achieving the second objective of identifying FCSIT staffs and students attitude towards energy conservation, questionnaires were distributed to these respondents. Lastly, the third objective is achieved by doing a simulation to calculate the estimated cost of the electricity wastage.

In this study, the estimated amount of electricity wastage in FCSIT building is obtained. Their is consumer awareness towards energy saving, and also the importance of the energy saving, but consumer behavior towards energy saving needs to be improved. Hence the need to consider implementing an appliance that can help in reducing electricity wastage, such as a light sensor. By implementing a sensor, the cost of electricity wastage can be reduced.

Based on this research, the future works to this research can be expanded as follows: 
(i) To make more solid simulations that can represent the real-world situation perfectly

(ii) Identify the electricity wastage in additional buildings

\section{REFERENCES}

[1] Aswani, A., Master, N., Taneja, J., Culler, D. \& Tomlin, C. (2012). Reducing Transient and Steady State Electricity Consumption in HVAC Using Learning-Based ModelPredictive Control. Proceedings of the IEEE, Vol. 100, No. 1, pp 240-253.

[2] Banks, J., Carson, J., Nelson, B., Nicol, D. (2000). Discrete-Event System Simulation, Prentice Hall (3rd ed.).

[3] Farhanieh, B. \& Sattari, S. (2006). Simulation of Energy Saving in Iranian Buildings using Integrative Modelling for Insulation. Renewable Energy, Vol. 31, No. 4, pp 417-425.

[4] Hartungi, R. \& Jiang, L. (2011). Achieving Energy Efficiency in Office Building. Smart Innovation, Systems and Technologies, Vol. 7, pp 1-13.

[5] Iqbal, I. \& Al-Homoud, M. (2007). Parametric Analysis of Alternative Energy Conservation Measures in an Office Building in Hot and Humid Climates. Building and Environment, Vol. 42, No. 5, pp. 2166-2177.

[6] Lei, J. \& Ning, H. (2009). A New Method of LoadShedding Control on Centrifugal Water Chiller Sequencing. 2009 4th IEEE Conference on Industrial Electronics and Applications, pp 3204-3209.
[7] Office of Energy Efficiency. (2010). Retrieved from http://Bench marking energy performance.

[8] Oldewurtela, F., Parisiob, A., Jonesc, C. N., Gyalistrasa, D., Gwerderd, M., Stauche, V. \& Morari, M. (2012). Use of Model Predictive Control and Weather Forecasts for Energy Efficient Building Climate Control. Energy and Buildings, Vol. 45, pp 15-27.

[9] Ozoh, P., Abd-Rahman, S., Olayiwola, M. (2018). Developing Predictive Models using Typical Machine Learning and Computational Techniques, Analele Universităţii “Tibiscus”, Timişoara, Vol. 16, No. 2, pp. 82-85.

[10] Ozoh, P; Olayiwola, M., Adigun, A. (2018). An In- Depth Study of Typical Machine Learning Methods via Computational Techniques, Analele Universităţii “Tibiscus”, Timişoara, Vol. 16, No. 2, pp 77-81.

[11] World Energy Outlook (2019, May 31). Retrieved from. doi:10.1787/weo-2013-en/

[12] Yao, S., Song, Y., Zhang, L. \& Cheng, X. (2000). Wavelet Transform and Neural Networks for Short-Term Electrical Load Forecasting. Energy Conversion and Management, Vol. 41, No. 18, pp 1975-1988.

[13] Zamri, N., Mohammad, Z. \&Yusof, M. (2011). Study of Energy Efficiency Opportunities in UTHM International Journal of Environmental and Ecological Engineering, Vol. 5, No. 5, pp 313-319. 